\title{
A Message from our New CAEP President
}

\author{
Alecs Chochinov, MD, FRCPC*
}

I am writing this inaugural message in the afterglow of an enormously successful Canadian Association of Emergency Physicians (CAEP) annual conference, which not only beat all previous attendance records, but also featured an excellent scientific program that delivered on its promise of strengthening connections. Thanks to Drs. Eddy Lang and Grant Innes for spearheading the effort, to the countless volunteers from Calgary, track chairs and speakers from across the country, and to CAEP's head office for their superb organizational skills.

I've been asked multiple times about my "platform" as president and "vision" for the next two years. My standard response is that it is less about vision and more about helping the board and membership achieve their goals. CAEP is blessed with a very high-functioning board of directors, dedicated committee chairs, amazing members - and if I can serve them dutifully as president, I will have achieved success (to paraphrase my colleague Jim Christenson's frequent invocation of servant-leadership). Medical leadership is also about flexibility, so one must expect the unexpected and be prepared to adjust on the run. A term as CAEP president is a bit like a shift in the emergency department (ED). Having said all of this, it would be disingenuous to pretend I didn't also have my own platform. I do, and it comprises three planks.

The first relates to further defining the requisite competencies of an emergency physician (EP) and distinguishing features of an ED. As we evolve, it is vitally important to articulate who we are, our practice environment, and what our patients can expect of us when they are ill or injured. If not, others will do so for us. The recent College of Physicians and Surgeons of Ontario (CPSO) statement on rural emergency practice $^{1}$ is an example of how the colleges, acting in the interests of patients, will increasingly demand demonstrably higher standards of emergency care. CAEP's definitions statement ${ }^{2}$ has allowed us to take substantial ownership of this issue, as we should. We are 40 years old as an organization, roughly 35 as a recognized specialty in Canada, and we must continue to advance and define our discipline.

At the same time, we cannot ignore stark realities or undermine the many skilled generalist physicians who are practicing outside urban areas. CAEP is firmly committed to collaborating with the Society of Rural Physicians of Canada (SRPC) and to providing educational and preparatory opportunities to challenge certifying examinations. Our recent press release, ${ }^{3}$ in response to the CPSO statement on rural ED care, is evidence of our support in that regard. But, in the end, we must represent excellence in emergency care, and our eyes must be on the future of $\mathrm{EM}$, not the past.

The second plank is one of financial sustainability, which, in CAEP's case, is three-pronged: membership, continuing professional development (CPD), and our annual conference. We depend on all three to fund key member benefits, such as the journal you are now reading. Like a business, at any given time, one unit can suffer, but the business can still prosper if the others are contributing. Ideally, however, all units should be thriving. Currently, CAEP produces excellent CPD that generates substantial revenue but very little profit, and that must change.

Dr. Sean Moore has been entrusted by our board with the responsibility to help ensure that CAEP maintains both the quality and financial health of our CPD programs. One of our CPD priorities for the coming year is to establish a preparatory course for those wishing to challenge the Canadian College of Family Physicians Emergency Medicine (CCFP-EM) exam on a practiceeligible basis. If we are to be a positive force in the effort to increase the number of certified EPs, we must give our practice-eligible colleagues the tools to succeed. Like any major educational initiative, this will require an investment of resources, illustrating why program quality and financial health are inextricably intertwined.

From the *Head, Department of Emergency Medicine, Rady Faculty of Health Sciences, University of Manitoba; Medical Director, Emergency Program, Winnipeg RHA; and President, Canadian Association of Emergency Physicians. 
CAEP is very fortunate to house clinicians and researchers, urban and rural physicians, and multiple emergency medicine (EM) special interest groups in a single entity - like interlinked parts of a living, organic being. In that being, research is our lifeblood, or perhaps more like our marrow - precursor, pluripotent, invisibly incubating that which will nourish our moving parts and allow us to mature. Without research, we would eventually stagnate, involute, and cease being a viable specialty. Canada, especially for its size, has a preeminent place in the EM research firmament; however, we need additional revenue sources to fund this and other worthy endeavours, such as the laudable work that our partners in the International Federation of Emergency Medicine (IFEM) are doing with the World Health Organization (WHO) to develop emergency systems in developing countries. I would like to have an open discussion with our members about whether a small percentage of all revenue should go directly to support important aspects of EM that cannot generate their own income but are intrinsic to our mission and vision.

The third of my 3 planks (that must seem more like 30) is EP wellness. We have careers that are simultaneously immensely rewarding, cognitively and emotionally draining, and occasionally physically dangerous. Both residents and established clinicians suffer high rates of depression and dissociation. ${ }^{4}$ The recent, untimely death of one of our former EM residents is a call to action, and CAEP must step into the breach.

How can CAEP contribute meaningfully to its members' wellness? Firstly, as was abundantly clear in Calgary, our annual conference builds community, and the power of connection is every bit as important as education to the quality and longevity of our careers., ${ }^{5,6}$ Of note, at the Rising Stars session at the conference, three of the six excellent presentations addressed issues of stress and resiliency in the ED. Admitting to the problem is the first step, but we must do more. Stay tuned for information on a new CAEP wellness committee that is being formed, whose mission will be to work in conjunction with the university-based initiatives across Canada to create a panCanadian wellness program that is accessible to all.
For most of us, our most profound and lasting impact on the lives of others is not our intellect, or wit, or material gifts - it is how we make others feel in our presence. But, as we heard at two separate plenaries in Calgary on the subject of empathy, our capacity to give the gift of kindness to others depends on our own state of health. How do your patients feel when they leave the ED - cared for, listened to, or cursorily dismissed? Are you able to be kind, or are you hurting too much trying to cope or keep up? What does that say about our workplace?

If I could personify CAEP, I would want it to maintain its high standards but be truly empathic towards its members, even if we weren't on the same side of every issue. Also, I'd want it to be a place where residents and attending physicians could find peer support, community, comfort, and encouragement when times were tough, as they are for each one of us at one time or another.

That is my vision for CAEP in the next two years and beyond. With the dedication of our staff, board, and incredibly gifted members, it can be realized.

\section{REFERENCES}

1. The College of Physicians and Surgeons of Ontario. Expectations of physicians not certified in emergency medicine intending to include emergency medicine as part of their rural practice. Changing scope of practice process. Available at: http://www.cpso.on.ca/CPSO/media/ documents/Policies/Policy-Items/Expectations-Physicians-Emerg-MedRural-Practice.pdf (accessed on June 11, 2018). Note: the original statement was modified after responses by CAEP, CFPC and SRPC

2. McEwen J, Borreman S, Caudle J, et al. Position statement on emergency medicine definitions from the canadian association of Emergency Physicians. C7EM 2018;20(4):501-6.

3. Canadian Association of Emergency Physicians. The Canadian Association of Emergency Physicians' (CAEP) response to the College of Physicians and Surgeons of Ontario (CPSO) policy on expectations of physicians not certified in emergency medicine intending to include emergency medicine as part of their rural practice changing scope of practice process; 2018. Available at: https:// caep.ca/wp-content/uploads/2018/06/PressRelease-Rev-

CPSOstatement-FINAL-V3.pdf (accessed on June 12, 2018).

4. Berger E. Physician burnout. Ann Emerg Med 2013;61(3):A17-9.

5. Taher A, Crawford S, Koczerginski J, et al. Position Statement on Resident Wellness. CFEM 2018;epub, doi:10.1017/cem.2018.8.

6. Takayesu JK, Ramoska EA, Clark TR, et al. Factors associated with burnout during emergency medicine residency. Acad Emerg Med 2014;21(9):1031-5. 